\title{
ТРАНСЛАТОЛОГИЧЕСКИЕ ОСОБЕННОСТИ ЦВЕТООБОЗНАЧЕНИЙ В СОПОСТАВЛЕНИИ ПОЭТИЧЕСКИХ ТЕКСТОВ П. Б. ШЕЛЛИ НА АНГЛИЙСКОМ ЯЗЫКЕ И К. Д. БАЛЬМОНТА НА РУССКОМ
}

Статья посвящена комплексному исследованию цветообозначений в переводческом ракурсе. Поэтический материал, представленный работами английского поэта Перси Биши Шелли (The Revolt of Islam, The Sensitive Plant, Ginevra, Marenghi, The Cloud, To Jane: The Recollection, The Cenci: A Tragedy in Five Acts. Dedication, to Leigh Hunt Esquire, Arethusa, England in 1819, A Vision of The Sea, Ode to The West Wind), послужил ресурсом выборки колористической лексики на английском языке, а переводы данных работ, выполненные К. Д. Бальмонтом - на русском. Впервые представлено комплексное описание цветообозначений в поэтических текстах П. Б. Шелли, произведена их классификация, описаны особенности их функционирования. Теоретические и практические выводы о количественном преобладании хроматических единиц над ахроматическими, номинативов над колоративами, немотивированной колористической лексики над мотивированной, основных ЦО над смешанными, сложными и референтными, говорит о том, что лингвоцветовая картина мира поэта состоит в основной массе из ярких, и в то же время простых, легко доступных для восприятия языковых единиц. Данное исследование углубляет знания о лингвоцветовой картине мира Шелли и расширяет представление об эстетике лексики цветообозначений в поэтических текстах. Малочисленный состав индивидуально-авторских ЦО ставит под сомнение полновесность их основного статуса. Количественные данные сопоставительного анализа творческих подходов и транслатологических решений класса цветообозначений К. Д. Бальмонтом выявили инструментарий переводческих трансформаций: дословный перевод, опущение и реметафоризация/метафоризация. Исследователь также отмечает, что тексты, созданные автором перевода, оказали на адресата в той или иной мере схожее воздействие, как и оригинал, а значит, достигнута коммуникативно-функциональная эквивалентность в произведениях на русском языке. Владение данными знаниями позволяет переводчику экономить время и сконцентрироваться на решении нетривиальных задач.

Ключевые слова: цвет, цветообозначение, поэтический текст, ахроматические и хроматические цвета.

\section{A. A. Gorzhaya}

\section{TRANSLATOLOGICAL FEATURES OF COLOUR NAMING IN COMPARISON OF P. B. SHELLEY'S POETIC TEXTS IN ENGLISH AND K. D. BALMONT'S IN RUSSIAN}

The paper investigates the colour terms in the translation perspective. Poetic material presented by the works of the English poet Percy Bysshe Shelley (The Revolt of Islam, The Sensitive Plant, Ginevra, Marenghi, The Cloud, To the Jane: The Recollection, The Cenci: A Tragedy in Five Acts. Dedication, to Leigh Hunt Esquire, Arethusa, England in 1819 , A Vision of The Sea, Ode to The West Wind) served as a resource for sampling colouristic vocabulary in English, and translations of these works by K. D. Balmont in Russian. For the first time, a complex description of colour terms in the poetic texts of P. B. Shelley is presented, their classification is performed, and the features of their functioning are described. Theoretical and practical conclusions about the quantitative prevalence of chromatic units over the achromatic, nominative over the colorators, unmotivated colouristic vocabulary over the motivated, main colour namings over the mixed, complex and referential, means that the linguocolour world view of the poet mostly consists of bright, and at the same time simple, easily comprehen- sible language units. This study extends knowledge about the linguocolour world view of Shelley and expands the idea about the aesthetics of the vocabulary of colour terms in poetic texts. The small number of individual author colour namings casts doubt on the soundness of their main status. The quantitative data of a comparative analysis of creative approaches and translatological solutions of the colour designation class by $\mathrm{K}$. D. Balmont revealed the tools of translation transformations: literal translation, omission and remetaphorization/metaphorization. It must be noted that the texts created by the author of the translation have had a similar effect on the addressee, as it had on the original one. It means that a communicative-functional equivalence has been achieved when creating texts in Russian. With this in mind a translator can save his time and concentrate on solving non-trivial tasks.

Key words: colour, colour naming, poetic text, achromatic and chromatic colours. 
Окружающая действительность воспринимается нами в цвете, и этот факт, несомненно, является значимым. Цвет, как один из основных признаков несознательного восприятия, концептуализации и категоризации мира, обладает огромной силой воздействия и играет важную роль в процессах познания окружающей действительности. Облачаясь в форму слова, цветовой образ становится предметом изучения языкознания. На уровне языка определенное межкомпонентное соединение понятий цветовой и нецветовой лексики обуславливает тот факт, что посредством цветообозначающих языковых единиц могут быть выражены многие стороны человеческой жизни и онтологически обусловлены визуальные характеристики объекта.

Особым способом организована речь, неопределенная потребностями обыденного языка, в поэзии. Интерес к поэтическому тексту не ослабевает ввиду наличия большой смысловой нагрузки на каждое отдельно взятое слово. В данной разновидности речевой деятельности всегда прослеживается особая авторская интенция, и, помимо собственного содержания, в той или иной степени проявляет себя имплицитная информация. В этом случае учитывается не только содержание, но и форма. Цветовой спектр приобретает самые различные оттенки благодаря особой организации текста и повышенной активизации всех его уровней. Особый интерес вызывает колористическая лексика в поэтических текстах Перси Биши Шелли. Цвет в творчестве стихотворца вписан в поэтическую картину мира и выступает в качестве целостной и завершенной модели окружающей действительности.

Цель данной работы - выявить транслатологические особенности лексики цветообозначений (ЦО) с английского языка на русский на материале поэтических текстов Перси Биши Шелли и их переводах, выполненных Константином Дмитриевичем Бальмонтом.

В данной работе мы предлагаем рассматривать понятие «цветообозначение», суть которого более полно раскрывает Е. А. Горн, как «единицу, принадлежащую, как к системе языка, так и к системе речи, выраженную любыми средствами от морфемы до сверхфразового единства, имеющую в своем значении лексическую прямую или опосредованную ассоциативную связь с цветом». В поэтическом тексте цветообозначения выполняют различные функции, такие как номинативую, аттрактивную, изобразительную и эстетическую.

По мнению 3. И. Комаровой и М. Б. Талапиной, концепт цвета «представляет собой схему восприятия, в соответствии с которой у всех объектов окружающего нас мира выделяется характеристика «окрашенности», передаваемая в языке посредством прилагательных цвета» [3, р. 33].

Однако смысл даже первичных цветов не может быть универсальным, поскольку в некоторых случаях обозначение цвета отсутствует в языке. А исторические прототипы цветов, связанных с той или иной частью спектра, придали свои оттенки значению цветообозначения.
Для переводческого исследования в данной статье, в целях более глубокого понимания цветовой картины мира П. Б. Шелли, интерпретирующего колоративную лексику как способ психологизации нарратива, особый интерес представляет классификация М. В. Мироновой, которая выделяет пять типов прилагательных цветообозначения. К ним относятся основные (red, blue, green, yellow, black, white), смешанные (оранжевый = желтый + красный (orange = yellow + red), фриолетовый $=$ синий + красный $($ violet $=$ blue + red $)$, сложные (темно-зеленый, ярко-красный, light blue, dark red), ресерентные - названия растений, животных, птиц, минералов, еды и напитков (ginger, mint, hazel, flamingo, lilac) и, наконец окказиональные или индивидуально-авторские цветообозначения (бледно-скромный, желто-бархатный, твердо-алый). Подобные ЦО широко используют авторы художественных произведений, в которых прилагательные несут дополнительные внутритекстовые значения (прямые, метафорические, символические и т.п.) и несут идейно-художественную нагрузку [5, р. 100].

Довольно распространенной является типологизация цветов на ахроматические (черный, серый, белый) и хроматические («пестрые»), основанная на онтологическом противопоставлении света и тьмы (Р. М. Фрумкина (1984), Н. В. Серов (1995), А. П. Вежбицкая (1996), П. В. Яньшин (2006)). При изучении реализации эстетической и изобразительно-выразительной функций языка важным является подразделение наименований цвета на нейтральные (номинативы) и стилистически маркированные (колоративы), которые принято называть ЦЦО фигурального характера, способными порождать художественную речь (Н. А. Мартьянова (2007).

Индивидуально-авторскую цветовую картину мира принято классифицировать по наличию или отсутствию мотивированности, согласно которой можно говорить о мотивированных именах цвета и наименованиях, таковой не обладающих. Поскольку мотивированные ЦО образованы от наименований различных объектов реальной действительности и обладают ярко выраженной этимологией, например: golden, snow-white, olive и т.д., их можно назвать объектными именами цвета [3, р. 218].

Нашу исследовательскую базу составили произведения, написанные Перси Биши Шелли в разные годы жизни, а именно: The Revolt of Islam (a fragment) (1817), The Sensitive Plant (1820), Ginevra (1821), Marenghi (1818), The Cloud (1820), To Jane: The Recollection (1822), The Cenci: A Tragedy in Five Acts. Dedication, to Leigh Hunt Esquire (1819-1820), Arethusa (1820), England in 1819 (1819), A Vision of The Sea (1820), Ode to The West Wind (1819), а также их переводы, выполненные Константином Дмитриевичем Бальмонтом: «Возмущение Ислама (Лаон и Цитна)», «Мимоза», «Джиневра», «Маренги», «Облако», «Воспоминания к Джен», «Ченчи», «Аретуза», «Англия в 1819 г. Сонет», «Морское видение», 
«Песнь к западному ветру», которые были взять из различных сборников и интернет-источников

Для анализа были выбраны произведения, представляющие собой различные литературные, в частности, лирические и поэтические жанры, такие как: трагедия, поэма, лирическое стихотворение, ода, сонет, басня. Подробные переводческие комментарии будут даны к тем примерам, которые, на наш взгляд, являются в эмпирической базе наиболее яркими и образными.

Текстовое пространство поэтических произведений П. Б. Шелли насыщено различными ЦО, такими как: red, green, golden, azure, crimson black, blue, yellow, purple, orange-coloured и их оттенками разной степени интенсивности: hoary gray, faint crimson, dark-red, tender green. Благодаря способности автора мастерски осваивать весь спектр цветовых терминов своей культуры, создается впечатление большого количества используемых красок. Все это обогащает знания читателя об окружающем мире и человеческой личности, как его важного компонента.

Итак, в рамках ранее заявленных нами классификаций цветообозначающей лексики, а также в ходе анализа эмпирического материала, включающего в себя 153 примера колоративной лексики, которые были отобраны методом сплошной выборки, мы выделили 94 хроматических (red, purple, blue, silver, yellow, brown, golden и т.д.) и 59 ахроматических единиц (white, black, gray и т.д.)

Эмпирическую базу с позиции подразделения цветов на нейтральные (номинативы) и стилистически маркированные (колоративы) цвета, которые также принято называть ЦО фигурального характера, составили 103 примера ЦЦО-номинативов (green, black, brown, white, red и т.д.) и 50 примеров ЦО-колоративов (golden, emerald, silver, azure, milky и т.д.).

Говоря о мотивированных ЦО, можно выделить 39 цветообозначений (snowy, golden, leadcoloured, ivory, blood-red и т.д.), и немотивированных ЦЦО - 114 единиц (blue, black, red, green, sanguine и т.д.).

Согласно идентификаторам цветовых тегов, предложенным М. В. Мироновой, мы выделили 83 основных (red, blue, yellow, black, white, green и т.д.), 22 смешанных (orange-coloured, purple, gray, crimson и т.д.), 10 сложных (many-coloured, darkred, golden-pinioned, deep-red, lead-coloured и т.д.), 34 референтных (silver, golden, dewy, emerald и т.д.) и, наконец, 4 окказиональных или индивидуально-авторских цветообозначения (night-black, moonlight-coloured, million-coloured, hectic-red), которые составляют дополнительные внутритекстовые значения в произведениях П. Б. Шелли и несут особую идейно-художественную нагрузку, но чей небольшой состав позволяет поставить под сомнение полновесность их основного статуса.

Поскольку исследуемый поэтический текст заключает в себе индивидуально-авторскую художественную картину мира и содержит в себе языковые особенности авторской / субъективной поэтической номинации, а также лингвистические особенности объективного / инвариантного язы- кового мышления, мы причисляем его к антрополингвистической категории

Как результат языкового творчества, транслатологическая характеристика поэтического текста подразумевает, что переводчик, как субъект коммуникации, должен генерировать новый поэтический текст, равноценный оригиналу по его концептуальной и эстетической информации, но использующий по необходимости совсем иные языковые, а порой и стиховые формы [1, р. 25]. Интерпретатор, интегрируя в создаваемое произведение, декодирует вербально-художественную информацию оригинала в соответствии с переводческой, личностной, культурной, языковой установками [6, p.11], он обрабатывает поступающую информацию на двух уровнях: как переводчик-читатель и как переводчик-поэт.

Bce трансляционные преобразования основаны на одной или двух речемыслительных операциях, это - парафраз и / или замена. Однако уровень межъязыковых трансформаций может значительно варьироваться, это могут быть преобразования, обусловленные некоторыми отличиями оригинала и переведенного текста. Наблюдаются ситуации, когда текст перевода и текст оригинала имеют разную словесную форму, то есть текст перевода сложно определить как перевод оригинального текста. Только в результате детального сопоставления можно сделать вывод, что такой вид перевода наиболее приемлемый, и именно он позволяет наилучшим образом передать оригинал реципиенту.

С точки зрения перевода цветообозначений в таком типе текста, интерес вызывает тот факт, что поэтический текст дополнительно ограничивается метрико-ритмическими нормами, организованностью на всех уровнях его структуры. В процессе передачи текста оригинала на язык перевода возникают трудности, обусловленные различиями систем версификации в разных языках, а также расхождением структур фонетики, лексики, стилистики, а также грамматики.

Компетентность в технике перевода и умение применять ее на практике экономят переводчику время и позволяют сосредоточиться на решении нетривиальных задач. Однако только два этих фактора не всегда способствуют успешному переводу, поскольку любой вид трансформации требует от переводчика творческого подхода и определенных решений для создания равноценного текста на языке перевода.

По итогам анализа перевода исследуемых произведений, выполненного К. Д. Бальмонтом, в которых автором порождаются новые образы, обладающие определенными цветовыми характеристиками, выявлено, что большинство хроматических цветообозначений передано при помощи следующих грамматических и лексико-грамматическихтрансформаций, такихкак: опущение (30\%), дословныйперевод (28\%), реметафоризация $(7 \%)$ а также лексико-семантической модификации эмфатизации (6 \%). 29 \% распределились между наименее частотными приемами: добавление, деметафоризация, целостное преобразование, расщепление и свертывание образа. 
Прежде всего, стоит отметить особенности организации двух уникальных примеров хроматических ЦО в сонете England 1819 («Англия в 1819 году. Сонет»), посвященном тяжелой социально-политической ситуации в годы правления короля Георга III. Сонет является одним из самых смелых политических заявлений Шелли. Лексические средства необычайно яркие и образные, что свидетельствует о глубоких переживаниях Шелли.

Golden and sanguine laws which tempt and slay; Religion Christless, Godless - a book sealed;

A senate, Time's worst statute, unrepealedAre graves from which a glorious Phantom may Burst, to illuminate our tempestuous day.

\section{Свирепые подкупные законы,}

Что в петлю завлекают и казнят, -

Святоши, что везде рождают стоны, -

Гнуснейший хлев, безмысленный Сенат, -

То черные могилы, из которых

Да встанет Призрак, с пламенем во взорах!

Референтное ЦО golden в данном фрагменте несет смысл подкупности политических деятелей и судей. В то время как деметафоризация (прием замены метафорического способа выражения мысли прямым) эмоционального каузатора sanguine, имеющее такие эквивалентные соответствия, как: 1) оптимистический; оптимистичный, 2) румяный (о лице), 3) кроваво-красный, отображает двойственный характер этих законов и весь ужас кровопролития, которое явилось результатом функционирования подобных коррупционных механизмов в Англии.

Одно из самых известных стихотворений Шелли 1820 года - The Sensitive Plant («Мимоза»), написано в четыре строфы, в жанре басни. Bce образы в произведении аллегоричны с садом, представляющим райский мир, а Леди, ухаживающая за садом - мать-природа, которая заботится обо всем живом и является не чем иным, как душой сада.

And on the stream whose inconstant bosom Was pranked, under boughs of embowering blossom,

With golden and green light, slanting through

Their heaven of many a tangled hue,

Broad water-lilies lay tremulously,

Под ласковой тенью зеленых ветвей Под искристым светом горячих лучей, Над гладью изменчивой, гладью речной Дрожали кувшинки, целуясь с волной;..

В данном примере переводчик расщепил образ колоративного green light на под ласковой тенью зеленых ветвей, при этом их суммарный образный потенциал примерно совпадает с образным потенциалом исходной единицы, созданным Шелли. В свою очередь, реметафоризация цветового образа golden light, несущего фигуральный харак- тер, была заменена на описательный оборот (т.е. используется нецветовая лексика) «искристым светом горячих лучей», что не только сохраняет авторский образ, но и эмфатизирует его.

Ахроматический фрагмент лингвоцветовой картины мира репрезентируется в поэзии Шелли цветообозначениями, которые обладают разным прагматическим потенциалом. Основные ахроматические цвета организующие «цветовое пространство» произведений Шелли это black и white. Остальные цветообозначения манифестируют периферийные признаки ахроматического фрагмента произведений поэта.

Большинство ахроматических ЦЦО были переведены при помощи дословного перевода (27 \%), с целью сохранения эквивалентности, а также при помощи опущения (17\%), метафоризации (11\%) и замены фрормы слова (11\%). В случае если образ невозможно было передать в полной мере переводчик создавал свой, иногда более сильный образ с яркой стилистической окраской (добавление, конкретизация, метонимическая трансформация, перераспределение содержания, целостное преобразование, расщепление образа (в целом процентное соотношение данных модификаций составило $34 \%)$ ).

Стихотворение A Vision of The Sea («Морское видение») описывает мощь и силу водной стихии - шторм на море и затерявшийся в нем корабль, на котором один за другим погибают все моряки. Когда буря стихает и сквозь тучи проглядывает солнце, в живых остаются только мать и дитя, к которым вскоре приходит помощь. Стоит отметить, что манера, в которой написано это стихотворение, напоминает манеру написания текстов, в гипнотическом состоянии или так называемое «автоматическое (механическое) письмо».

From the stark night of vapours the dim rain is driven,

And when lightning is loosed, like a deluge from Heaven,

She sees the black trunks of the waterspouts spin

And bend, as if Heaven was ruining in...

Из туманов, уарюмых, как чернеющий ароб, Вместе с молнией хлынул многоводный поmon.

Напряженные смерчи, как подпоры небес,

Поднимаясь, коснулись этих темных завес,

И тяжелое небо так повисло на них,

Что они пошатнулись и в алубинах морских...

В данном примере утраченное номинативное цветообозначение black, в словосочетании 'black trunks' было компенсировано фразой «темных завес", что позволило переводчику сохранить образность и прагматический потенциал ИЯ

Произведение Ginevra («Джиневра»), которое Шелли пишет в 1821 году, повествует о девушке по имени Джиневра, которая по воле семьи вышла замуж за нелюбимого человека, однако сердцем и душой осталась верна возлюбленному 
Антонию. Невеста умирает в день своей свадьбы, вызывая всеобщую скорбь, и лишь только ее жених Герарди не горюет о ее смерти: «...И тупо утешенья слушал он, в которых не нуждался: не зажжен любовью был в нем дух».

В произведении часто встречаются нейтральные ЦЦО, описывающие внешний облик невесты, как при жизни, так и после нее:

They found Ginevra dead! if it be death

To lie without motion, or pulse, or breath,

With waxen cheeks, and limbs cold, stiff, and white..

Увы, они нашли Джиневру мертвой.

Да, мертвой, если это смерть - лежать

Без пульса, не вздыхать и не дыиать,

Быть белою, холодной, восковою...

С целью сохранения метрико-ритмической структуры произведения переводчик в данном примере использует замену формы прилагательного white на форму женского рода в творительном падеже - белою. Также для усиления эмфратического эфффекта и в целях прагматической адаптации образа, созданного Шелли, к русской лингвокультуре, переводчик посчитал возможным применить синекдохическую транссормацию: признаки “смерти» он переносит с частей тела (щек, конечностей и т.д.) на все тело Джиневры.

Так, большинство ахроматических цветообозначений были переданы при помощи дословного перевода, что говорит о стремлении автора сохранить эмоционально-экспрессивную составляющую поэтических текстов П.Б. Шелли. В исключительных случаях, переводчик применяет замену формы слова, синекдохическую трансформацию или компенсацию с целью сохранения новой метрико-ритмической формы, созданной при переводе.

Далее приведем примеры уникальных цветовых индивидуально-авторских образов. В нашей картотеке таких единиц, несущих формальносемантический характер, выявлено четыре, а именно: night-black, moonlight-coloured, millioncoloured, hectic-red. Индивидуально-авторские цветообозначения переведены при помощи приемов нейтрализации и компенсации, использованных одновременно в одном примере (50\%), приемы опущения и целостного преобразования реализованы во второй цветообозначающей единице (24\%). Также выявлены трансформации генерализации (13\%) и деметаффоризации (13\%) с заменой цветовой лексики при помощи нецветовой.

Так, в произведении The Sensitive Plant (Мимоза) разные объекты живой природы - например цветы, описываются как небесные светила. Их лепестки, бутоны светят как звезды, а звезды в свою очередь появляются в небе или отражаются в воде.
And the wand-like lily, which lifted up, As a Maenad, its moonlight-coloured cup, Till the fiery star, which is its eye,

Gazed through clear dew on the tender sky;

И лилия светлую чашу взяла

И вверх, как Вакханка, ее подняла,

На ней, как звезда, загорелась роса,

И взор ее глаз устремлен в небеса;

Прекрасный «лунный» образ лилии, созданный Шелли при описании цвета её чашечки (мотивированная лексема 'moonlight-coloured'), в процессе перевода теряется (светлую). Переводчик стирает черты авторского стиля, применяя приемы компенсации и нейтрализации, оправдывая это сохранением оригинальной формы строфы (четверостишие с рифмовкой аабб).

Отождествляя себя с осенним западным ветром в Ode to the West Wind (Ода западному ветру), поэт Шелли наделяет его символическими функциями (своими дикими порывами он разносит по земле крылатые семена возрождения)

Yellow, and black, and pale, and hectic-red,

Pestilence-stricken multitudes: O thou,

Who chariotest to their dark wintry bed

Бегут листы и кружатся толпой,

Тая в себе всех красок сочетанье,

Объятье губительной чумой.

Осенние листья в приведенном выше фрагменте, обозначенные немотивированными ЦО (Yellow, and black, and pale), совсем не такие, как мы себе их представляем - яркие, красочные, вместо этого они несут отрицательную коннотацию и создают довольно пугающий образ, автор сравнивает их с «толпой больных, привидений». Здесь четко прослеживается аллегория между цветами и четырьмя всадниками, которые являются вестниками апокалипсиса. Мотивированное ЦО hectic, которое в англо-русском словаре АВВYY Lingvo имеет эквивалентные соответствия чахоточный, туберкулезный, гектический, косвенно отсылает нас к образу одного из всадников, имя которого Чума или Мор. В примере использованы приемы опущения и целостного преобразования, т.е. синтез значения иными лексико-грамматическими средствами без семантической связи с исходной единицей, как результат неизбежной потери из-за расхождения форм стихосложения.

Таким образом, индивидуально-авторские ЦО представляющие собой особую подсистему, передать в поэтическом переводе достаточно трудно по причине расхождения норм английского и русского языков, а также по причине различия картин мира поэта и переводчика. Такой крупный переводчик, как К.Д. Бальмонт, справляется с данными трудностями при помощи нейтрализации и компенсации, опущения и целостного преобразования, генерализации, а также деметафоризации 
Проведенное нами исследование художественного творчества П.Б. Шелли, отражающего в своих произведениях человека, его эмоции, представление себя и других в цветовом пространстве, позволяет сделать следующие выводы: выявленное нами количественное преобладание хроматических единиц (из них незначительное количество - 4 контекста, составили индивидуально-авторские цветообозначения) над ахроматическими 94 и 59 соответственно, номинативов (103 единицы) над колоративами (50 единиц), немотивированной колористической лексики (114) над мотивированной (39) и основных ЦО (83 единицы) над смешанными, сложными и референтными (70) из общей классификации, предложенной М. В. Мироновой, говорит о том, что лингвоцвето- вая картина мира поэта состоит в основной массе из ярких, и в то же время простых, легко доступных для восприятия языковых единиц.

Что касается передачи содержания произведений Шелли средствами русского языка, количественные данные свидетельствуют о том, что подчиняясь общим правилам транслатологии класса цветообозначений К. Д. Бальмонт находит стратегический компромисс в дословном переводе, опущении и реметафоризации / метафоризации. Следует отметить, что, поскольку тексты, созданные автором перевода, оказали на адресата в той или иной мере схожее воздействие, как и оригинал, в произведениях на русском языке достигнута коммуникативно-функциональная эквивалентность

\section{Литература}

1. Бархударов Л. С. Язык и перевод: Вопросы общей и частной теории перевода. М.: ЛКИ, 2008. 240 с

2. Горн Е. А. Цветообозначения в художественном тексте на английском и русском языках в сопоставительно-переводческом аспекте (на материале современной английской литературы): дис. ...канд. филол. наук. Санкт-Петербург, 2014. $211 \mathrm{c}$.

3. Комарова 3. И., Талапина М. Б. Лингвоцветовая картина мира: ахроматический фрагмент: монография. Екатеринбург: УФУ, 2011. $220 \mathrm{c}$.

4. Лопатина Н. Р. О некоторых социокультурных и психологических аспектах прилагательных цвета // Сфера языка и прагматика речевого общения: Междунар. сб. науч. тр. Краснодар: КубГУ, 2003. С. 218-226.

5. Миронова М. В. Классификация прилагательных цвета (на примере цветообозначений русского и английского языков // Вестник АмГУ. 2009. Вып. 46. С.100-101.

6. Эткинд Е. Г. Поэзия и перевод. М.: Советский писатель, 1963. 431 с.

\section{References}

1. Barkhudarov L. S. Yazyk i perevod: Voprosy obshchei i chastnoi teorii perevoda (Language and Translation: Questions of General and Specific Theory of Translation). Moscow: LKI publ., 2008. 240 p. (In Russian)

2. Gorn E. A. Tsvetooboznacheniya v khudozhestvennom tekste na angliiskom i russkom yazykakh v sopostavitel'noperevodcheskom aspekte (na materiale sovremennoi angliiskoi literatury) (Colour Namings in the Fictional Text in the English and Russian Languages in the Comparative Translational Aspect (on the Material of Modern English Literature): dis. ...kand filol. nauk. Sankt- Peterburg, 2014. 211 p. (In Russian)

3. Komarova Z. I., Talapina M. B. Lingvotsvetovaya kartina mira: akhromaticheskii fragment (Linguocolour World View: Achromatic Fragment): monografiya. Ekaterinburg: UFU publ., 2011. 220 p. (In Russian)

4. Lopatina N. R. O nekotorykh sotsiokul'turnykh i psikhologicheskikh aspektakh prilagatel'nykh tsveta (On Some Sociocultural and Psychological Aspects of Colour Adjectives) // Sfera yazyka i pragmatika rechevogo obshcheniya: Mezhdunar. Krasnodar: KubSU publ., 2003. P. 218-226. (In Russian)

5. Mironova M. V. Klassifikatsiya prilagatel'nykh tsveta (na primere tsvetooboznachenii russkogo i angliiskogo yazykov (The Classification of Colour Adjectives (on the Example of Colour Terms of the Russian and English languages) // Vestnik AmGU. 2009. Issue. 46. P.100-101. (In Russian)

6. Etkind E. G. Poeziya i perevod (Poetry and Translation). Moscow: Sovetskii pisatel', 1963. 431 p. (In Russian)

\section{Сведения об авторе}

Горжая Алеся Александровна - кандидат филологических наук, доцент кафедры теории и практики перевода гуманитарного института Северо-Кавказского феедерального университета (Ставрополь) / kafedra.tipp@mail.ru

\section{Information about the author}

Gorzhaya Alesya - PhD in Philological Sciences, Associate Professor, Chair of translation studies, Institute for the Humanities, North-Caucasus Federal University (Stavropol) / kafedra.tipp@mail.ru 